\title{
ANALISIS STABILITAS MENGGUNAKAN MODEL MATERIAL PERALIHAN TANAH-BATUAN
}

\author{
Putera Agung, M.A ${ }^{\mathbf{1}}$, Ardianto, $\mathbf{A}^{\mathbf{2}}$ \\ ${ }^{1,2}$ State Polytechnic of Jakarta, Civil Engineering Department, Jalan Prof. Dr.G.A. Siwabessy, 16424, \\ putera.agungmagung@sipil.pnj.ac.id
}

\begin{abstract}
An analysis of stability needs to predict stress-strain values of soil, rock, and/or intermediate material (soil-rock) layers around the gate shaft during excavation works. Selection of stress-strain of intermediate material foccused on this paper will affect to the analysis result. This analysis concerned on some consideration to the selection the stress-strain parameters in determination of $c$ ' and $\phi$ ' parameters. In excavation works, the parameters were applied to the stability analysis of gate shaft construction of dam construction. The stability analysis used a 2 D software of PLAXIS. Each condition of gate shaft was reinforcement and un-reinforcement wall types. From several analyses, the parameters of c' and $\phi$ ' from stress-strain of soil was smaller than intermediate material.
\end{abstract}

Keywords: Cohesion; angle of internal friction, stress, strain, gate shaft.

\begin{abstract}
ABSTRAK
Suatu analisis stabilitas perlu untuk memperkirakan besarnya tegangan-regangan tanah, batuan, dan atau lapisan material peralihan tanah-batuan (intermediate material) di sekitar lubang galian vertikal. Pemilihan tegangan-regangan dari material peralihan tanah-batuan yang difokuskan pada paper ini akan berpengaruh terhadap hasil analisis. Analisis ini memusatkan perhatian pada beberapa pertimbangan pemilihan parameter tegangan-regangan dalam analisis stabilitas saluran pengalihn vertikal pada konstruksi dam. Analisis stabilitas ini menggunakan software Plaxis 2 D (dimensi). Masing-masing tipe dinding saluran vertikal ini adalah dengan dan tanpa perkuatan tulangan. Dari beberapa analisis, parameter c' dan $\phi$ ' dari tanah adalah lebih kecil dari material peralihan.
\end{abstract}

Kata kunci: Kohesi, sudut geser dalam, tegangan, regangan, saluran pengalihan vertikal.

\section{PENDAHULUAN}

Sistem perkuatan dinding lapisan tanah pada dinding saluran pengalihan vertikal (gate shaft) bergantung kepada model tegangan-regangan. Umumnya, desain sistem perkuatan adalah sangat bergantung kepada parameter c' and $\phi$ ' dalam suatu analisis stabilitas dinding saluran pengalihan vertikal. Model tegangan-regangan tanah adalah sangat berbeda dengan batuan, sehingga sangat diperlukan usaha-usaha signifikan untuk mengadakan pendekatan terhadap pemilihan model tegangan-regangan yang merefleksikan dengan kondisi asli lapisan tanah di lapangan (Atkinson \& Bransby, 1978; Hoek-Brown, 1980).

Saat proses penggalian suatu struktur tanah dan atau batuan, dan material peralihan tanah-batuan (intermediate material) secara vertikal (gate shaft) diperlukan suatu sistem perkuatan agar lapisan tanah tidak runtuh atau longsor.

Paper ini khusus membahas pemilihan model intermediate material sebagai kriteria keruntuhan material peralihan tanah-batuan untuk menentukan stabilitas dinding gate shaft di lokasi pekerjaan penggalian Bendungan Jatigede. Adapun semua profil lapisan 
intermediate material di lokasi studi Jatigede merupakan lapisan breksi (breccia) dan batulempung (claystone) yang terbungkus oleh lapisan pasir (sand) dan lempung (clay). Jenis lapisan tanah di lokasi penggalian vertikal merupakan lapisan-lapisan intermediate material yang mudah sekali rontok dan lapuk, sekalipun kelihatannya kokoh dan kaku saat proses penggalian. Ada beberapa teori yang digunakan untuk memprediksi tegangan-regangan pada lapisan tanah; batuan, dan peralihan material tanah-batuan. Model teganganregangan pada lapisan tanah umumnya adalah model Mohr-Coulomb untuk kondisi dengan pengaliran (drained), dan model Tresca untuk kondisi tanpa pengaliran (undrained). Namun, terdapat 2 (dua) teori yang penting di dalam menilai tegangan-regangan tanah pada saat keruntuhan tanah adalah teori batas kritis (critical state) dan keseimbangan batas (steady state). Model tegangan-regangan pada saat keruntuhan untuk lapisan batuan berperilaku daktil atau getas umumnya menggunakan Model Hoek-Brown kondisi elastis (perubahan volume) dan plastis (tanpa perubahan volume). Perbandingan tegangan-regangan saat keruntuhan antara model tanah dan pada model batuan terlihat dalam Gambar 1 .

\section{METODE PENELITIAN}

Dari Gambar 1, parameter c' dan $\phi$ ' dapat ditentukan untuk model intermediate material (tanah-batuan), dengan cara menyamakan parameter c' dan atau $\phi$ ' menurut Kriteria Persamaan Hoek-Brown (batuan) dan Persamaan Mohr-Coulomb (tanah), sehingga diperoleh (Hoek, 1980):

$$
c^{\prime}=\frac{\sigma_{c i}\left[(1+2 a) s+(1-a) m_{b} \sigma_{3 n}{ }^{\prime}\right]\left(s+m_{b} \sigma_{3 n}{ }^{\prime}\right)}{(1+a)(2+a) \sqrt{1+\frac{\left(6 \mathrm{am}_{b}\left(s+m_{b} \sigma_{3 n}{ }^{a-1}\right)\right.}{(1+a)(2+a)}}}
$$

$$
\begin{aligned}
& \phi^{\prime}=\sin ^{-1}\left[\frac{6 \mathrm{am}_{\mathrm{b}}\left(\mathrm{s}+\mathrm{m}_{\mathrm{b}} \sigma_{33^{\prime}}\right)^{\mathrm{a}-1}}{2(1+\mathrm{a})(2+\mathrm{a})+6 \mathrm{am}_{\mathrm{b}}\left(\mathrm{s}+\mathrm{m}_{\mathrm{b}} \sigma_{3 \mathrm{n}^{\prime}}\right)^{\mathrm{a}-1}}\right] \\
& \operatorname{dimana}, \sigma_{3 \mathrm{n}}{ }^{\prime}=\frac{\sigma_{3 \max }{ }^{\prime}}{\sigma_{\mathrm{ci}}}
\end{aligned}
$$

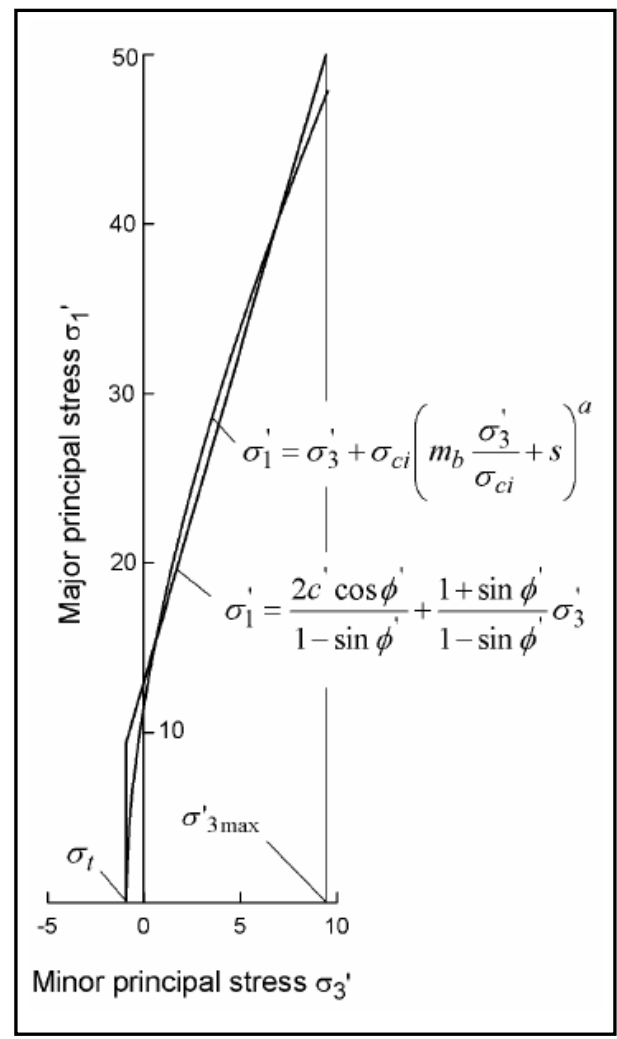

Gambar 1. Hubungan secara prinsipal antara tegangan mayor dan minor dalam model keruntuhan Mohr-Coulomb dan model Hoek-Brown (1980).

$\sigma_{3 \max }$ adalah batas atas tegangan terkekang (confining stress) yang ditentukan oleh hubungan MohrCoulomb dan Hoek-Brown. Dengan demikian jelas, bahwa $\sigma_{3 \max }$ dari HoekBrown dan Mohr-Coulomb merupakan lapisan dasar galian. Selanjutnya dari Gambar 1, nilai-nilai c' and $\phi$ ' diperoleh dapat ditentukan berdasarkan interval $\sigma_{\mathrm{t}}$ $<\sigma_{3}<\sigma_{\mathrm{ci}} / 4$ :

$\sigma_{c m}^{\prime}=\sigma_{c i} \frac{\left(m_{b}+4 s-a\left(m_{b}-8 s\right)\right)\left(m_{b} / 4+s\right)^{a-1}}{2(1+a)(2+a)}$

Dari laporan geologi gate shaft dan terowongan power waterway, profil lapisan intermediate material diperlihatkan Gambar 2. 
Lapisan breksi berasal dari lapisan bawah formasi geologi Halang. Sedangkan untuk lapisan batulempung adalah berasal dari lapisan atas formasi geologi Halang dan Cinambo (SMEC, 1974). Batuan dasar terdiri dari lapisan batulempung, breksi vulkanik dan breksi lokal tufaan atau atau lapisan tufaan lapilli. Lapisan-lapisan intermediate material ini telah diklasifikasikan berdasarkan beberapa referensi, seperti: Terzaghi (1946), Lauffer (1958), Deere et al., 1967); Bieniawski (1974, 1989); Singh \& Goel (1999), Barton (1974), dan Carter (1992). Data hasil bor untuk lapisan intermediate material ini diperlihatkan dalam Gambar 3.

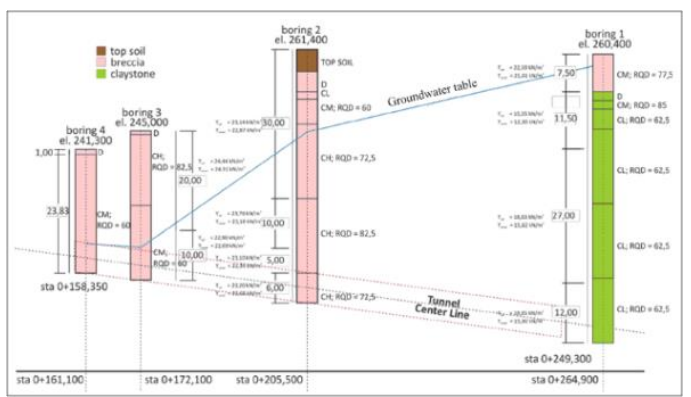

Gambar 2. Profil lapisan intermediate material (lapisan breksi, batulempung terbungkus lapisan pasir dan lempung)

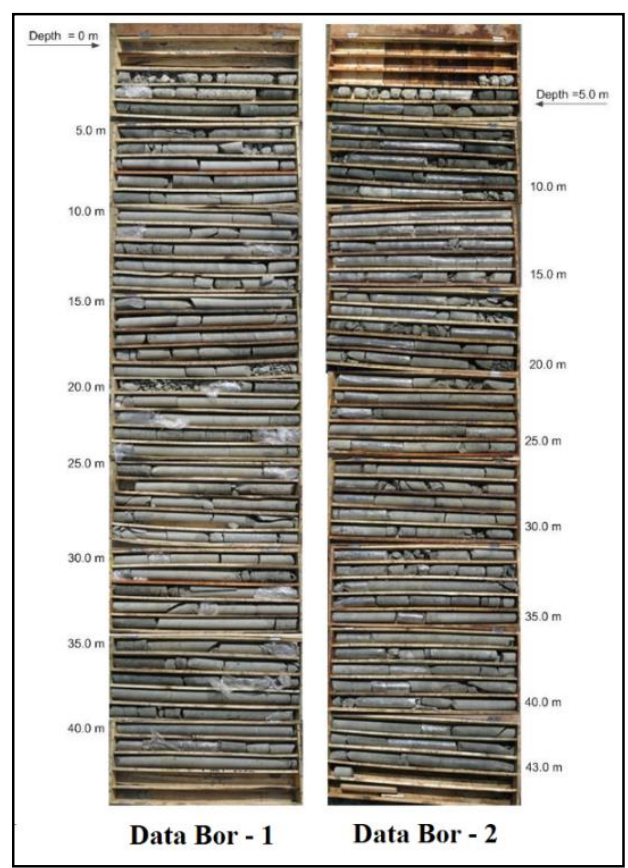

Gambar 3. Data bor tipikal
Parameter input untuk intermediate material pada Software PLAXIS 2 D (2007) ditentukan berdasarkan nilainilai RQD (rock quality designation) berdasarkan sistem klasifikasi Deere (1967), diperlihatkan dalam Tabel 1. Tabel 2 menunjukkan perkiraan nilai sifat kekuatan mekanik lapisan intermediate material di lokasi Jatigede. Sebagai pembanding, digunakan standar SMEC - Australia (2011) untuk menentukan parameter yang mendekati dengan intermediate material kondisi eksisting sebagaimana terlihat Tabel 3.

Table 1. Nilai RQD

\begin{tabular}{cccc}
\hline \multicolumn{2}{c}{ BH -1} & \multicolumn{2}{c}{ BH -3} \\
\hline $\mathrm{D}(\mathrm{m})$ & RQD \% & $\mathrm{D} \mathrm{(m)}$ & $\mathrm{RQD} \%$ \\
$3.7-43$ & $\begin{array}{r}40-80 \\
\text { (buruk) }\end{array}$ & $3.7-43$ & $\begin{array}{l}40-80 \\
\text { (buruk) }\end{array}$ \\
\hline
\end{tabular}

Table 2. Sifat mekanik dan kekuatan geser dari intermediate material

\begin{tabular}{cccc}
\hline Kelas & $\begin{array}{c}\mathbf{E}_{\mathbf{m}} \\
\left(\mathrm{kgf} / \mathrm{cm}^{2}\right)\end{array}$ & $\begin{array}{c}\mathbf{E} \\
\left(\mathrm{kgf} / \mathrm{cm}^{2}\right)\end{array}$ & $\begin{array}{c}\mathbf{V}_{\mathbf{s}} \\
(\mathrm{km} / \mathrm{sec})\end{array}$ \\
\hline $\mathrm{CH}$ & $2.0 .10^{4}$ & $6.0 .10^{4}$ & 2.5 \\
$\mathrm{CM}$ & $8.0 .10^{3}$ & $2.4 \cdot 10^{4}$ & 1.8 \\
$\mathrm{CL}$ & $4.0 .10^{3}$ & $1.2 .10^{4}$ & 1.5 \\
$\mathrm{D}$ & $2.0 .10^{3}$ & $6.0 .10^{3}$ & 1.2
\end{tabular}

\begin{tabular}{cccc} 
Kelas & \multicolumn{2}{c}{ Kuat geser } & $\mathbf{q u}$ \\
c' & $\boldsymbol{\phi}^{\prime}\left({ }^{\mathbf{0}}\right)$ & $(\mathbf{k g f} / \mathbf{c m} 2)$ \\
$\mathrm{CH}$ & 20 & 45 & $>500$ \\
$\mathrm{CM}$ & 10 & 35 & $100-500$ \\
$\mathrm{CL}$ & 8 & 30 & $40-100$ \\
$\mathrm{D}$ & 5 & 28 & $20-40$ \\
\hline
\end{tabular}

Table 3. Karakteristik intermediate material (SMEC-Australia, 2011)

\begin{tabular}{|c|c|c|c|c|c|c|c|c|}
\hline \multirow{2}{*}{$\begin{array}{c}\text { Tipe } \\
\text { Struktur }\end{array}$} & \multirow{2}{*}{$\begin{array}{c}\text { Tipe } \\
\text { material }\end{array}$} & Tebal & $w$ & $K_{0}$ & $\phi^{\prime}$ & $c^{\prime}$ & $E$ & $v$ \\
\hline & & $(m)$ & $\left(k N m^{3}\right)$ & & (deg) & (kPa) & (Mpa) & \\
\hline \multirow{2}{*}{$\begin{array}{l}\text { Dinding } \\
\text { galian } \\
\text { stasiun } \\
\text { tenaga } \\
\text { listrik }\end{array}$} & $\begin{array}{c}\text { Batulempung } \\
\text { buruk }\end{array}$ & 25 & 20 & 2.0 & 26 & 50 & 20 & 0.33 \\
\hline & $\begin{array}{l}\text { Batulempung } \\
\text { lebih baik }\end{array}$ & 55 & 21 & 2.0 & 30 & 150 & 200 & 0.33 \\
\hline
\end{tabular}

Koefisien permeabilitas untuk lapisan intermediate material di lokasi diambil 
berdasarkan data hasil uji permeabilitas lapangan yaitu $(\mathrm{k}) \approx 1.574 .10^{-5} \mathrm{~m} /$ day.

Selanjutnya, data input software PLAXIS 2 D untuk sistem perkuatan tanah (ground improvement) pada breksi vulkanik dan batulempung menggunakan pendekatan (sistem-Q) dari Grimstad \& Barton (1993). Untuk sistem perbaikan tanah lainnya adalah menggunakan beton tembak (shotcrete); baut batuan (rockbolt); perlapisan beton (concrete collar); dan sistem injeksi (grouting). Geometris dalam analisis software PLAXIS $2 \mathrm{D}$ adalah model sumbu simetris sama dengan jumlah nodal dalam 1 (satu) elemen. Lapisan atas breksi vulkanik adalah 5 hingga 7 $\mathrm{m}$, diikuti lapisan batulempung $47 \mathrm{~m}$. Lebar penampang penggalian secara adalah $61 \mathrm{~m}$ dengan ketinggian $55 \mathrm{~m}$.

\section{HASIL dan PEMBAHASAN}

Hasil analisis PLAXIS 2 D terdiri dari metode dengan proses penggalian tanpa dan dengan sistem perkuatan (ground improvement), yaitu:

\section{Tanpa perkuatan hingga proses penggalian $45 \mathrm{~m}$}

Tabel 4 menunjukkan data hasil pergerakan (displacement) total, arah vertikal, dan arah horizontal. Tabel 5 dan 6 menunjukkan tegangan total (total stress) dan efektif (effective stress).

Tabel 4. Pergerakan dinding galian

\begin{tabular}{|c|c|c|}
\hline Pergerakan & $\begin{array}{l}\text { Sisi } \\
\text { kiri }\end{array}$ & $\begin{array}{c}\text { Sisi } \\
\text { kanan }\end{array}$ \\
\hline Total (mm) & 440,44 & 187,53 \\
\hline Vertikal (mm) & 440,35 & 152,51 \\
\hline $\begin{array}{l}\text { Horizontal } \\
\text { (mm) }\end{array}$ & 209,65 & 182,10 \\
\hline
\end{tabular}

Tabel 5. Tegangan total

\begin{tabular}{ccc}
\hline $\begin{array}{c}\text { Tegangan } \\
\text { total }\end{array}$ & $\begin{array}{c}\text { Sisi } \\
\text { kiri }\end{array}$ & Sisi kanan \\
\hline$\sigma_{\max }\left(\mathrm{kN} / \mathrm{m}^{2}\right)$ & 974,36 & 895,89 \\
\hline
\end{tabular}

\begin{tabular}{ccc}
\hline $\left.\mathrm{F}_{\mathrm{eq}} \mathrm{kN} / \mathrm{rad}\right)$ & $340,24.10^{3}$ & $501,07.10^{3}$ \\
$\begin{array}{c}\text { Posisi (max) } \\
(\mathrm{m})\end{array}$ & $24,87 / 14,66$ & $36,23 / 14,98$ \\
\hline
\end{tabular}

Tabel 6. Tegangan efektif

\begin{tabular}{ccc}
\hline $\begin{array}{c}\text { Tegangan } \\
\text { total }\end{array}$ & $\begin{array}{c}\text { Sisi } \\
\text { kiri }\end{array}$ & Sisi kanan \\
\hline$\sigma_{\max }\left(\mathrm{kN} / \mathrm{m}^{2}\right)$ & 356,58 & 373,69 \\
$\left.\mathrm{~F}_{\text {eq }} \mathrm{kN} / \mathrm{rad}\right)$ & $278,24.10^{3}$ & $333,96.10^{3}$ \\
$\begin{array}{c}\text { Posisi }(\max ) \\
(\mathrm{m})\end{array}$ & $24,83 / 19,45$ & $36,24 / 18,77$ \\
\hline
\end{tabular}

\section{Dengan perkuatan hingga proses penggalian $45 \mathrm{~m}$}

Tabel 7 menunjukkan data hasil pergerakan (displacement) total, arah vertikal, dan horizontal. Tabel 8 dan 9 menunjukkan tegangan total (total stress) dan efektif (effective stress).

Tabel 7. Pergerakan dinding galian

\begin{tabular}{ccc}
\hline Pergerakan & $\begin{array}{c}\text { Sisi } \\
\text { kiri }\end{array}$ & $\begin{array}{c}\text { Sisi } \\
\text { kanan }\end{array}$ \\
\hline Total $(\mathrm{mm})$ & 249,98 & 165,91 \\
Vertikal $(\mathrm{mm})$ & 249,98 & 165,90 \\
$\begin{array}{c}\text { Horizontal } \\
(\mathrm{mm})\end{array}$ & 77,71 & 106,46 \\
\hline
\end{tabular}

Tabel 8. Tegangan total

\begin{tabular}{ccc}
\hline $\begin{array}{c}\text { Tegangan } \\
\text { total }\end{array}$ & $\begin{array}{c}\text { Sisi } \\
\text { kiri }\end{array}$ & Sisi kanan \\
\hline$\sigma_{\max }\left(\mathrm{kN} / \mathrm{m}^{2}\right)$ & 872,42 & 979,61 \\
$\mathrm{~F}_{\mathrm{eq}}(\mathrm{kN} / \mathrm{rad})$ & $586,36.10^{3}$ & $693,66.10^{3}$ \\
$\begin{array}{c}\text { Posisi }(\max ) \\
(\mathrm{m})\end{array}$ & $24,87 / 14,66$ & $36,23 / 14,98$ \\
\hline
\end{tabular}

Tabel 9. Tegangan efektif

\begin{tabular}{ccc}
\hline $\begin{array}{c}\text { Tegangan } \\
\text { total }\end{array}$ & $\begin{array}{c}\text { Sisi } \\
\text { kiri }\end{array}$ & Sisi kanan \\
\hline$\sigma_{\max }\left(\mathrm{kN} / \mathrm{m}^{2}\right)$ & 401,08 & 379,96 \\
$\mathrm{~F}_{\text {eq }}(\mathrm{kN} / \mathrm{rad})$ & $305,48.10^{3}$ & $244,0.10^{3}$ \\
$\begin{array}{c}\text { Posisi } \\
(\max )\end{array}$ & $36,17 / 19,56$ & $24,68 / 20,28$ \\
$(\mathrm{~m})$ & & \\
\hline
\end{tabular}

Perbandingan antara pergerakan horizontal tanpa dan dengan perkuatan selama proses penggalian berlangsung diperlihatkan di dalam Gambar 4. 

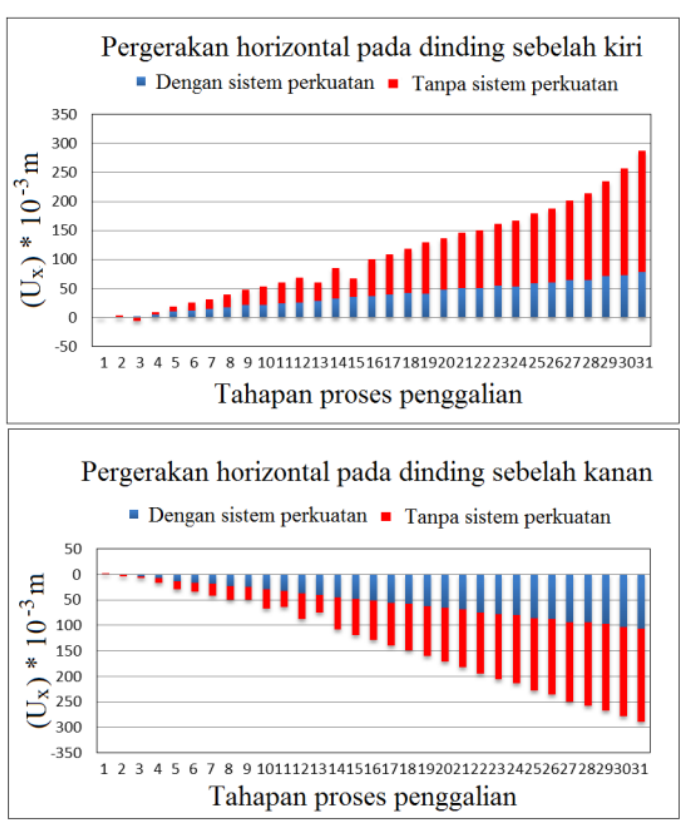

Gambar 4. Perbandingan pergerakan horizontal

Gambar 5 menunjukkan besarnya faktor keamanan selama proses penggalian.

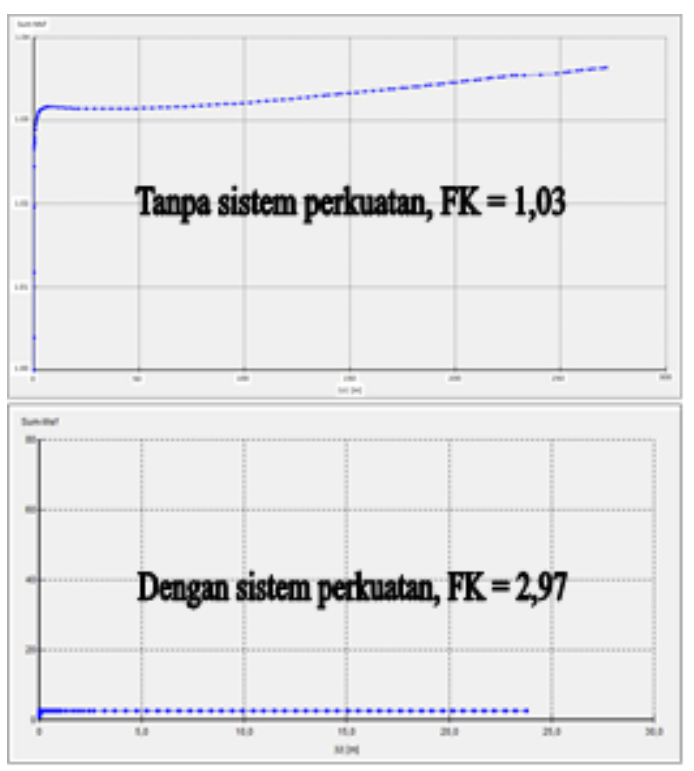

Gambar 5. Perbandingan angka/faktor keamanan (FK) antara tanpa dan dengan sistem perkuatan selama proses penggalian berlangsung

Dari aplikasi software PLAXIS 2 D pergerakan horizontal sebelah kiri jauh lebih besar daripada sebelah kanan selama proses penggalian berlangsung dengan menggunakan model teganganregangan untuk intermediate material. Umumnya, pergerakan horizontal yang besar disebabkan oleh lapisan batulempung. Untuk lapisan-lapisan breksi vulkanik, pergerakan yang terjadi umumnya lebih kecil dari batulempung.

Beberapa sistem perkuatan yang digunakan di dalam analisis stabilitas menghasilkan angka keamanan yang jauh lebih besar dari tanpa sistem perkuatan. Pemilihan model analisis stabilitas Agar lebih ekonomis bisa dipilih sistem injeksi (grouting), dimana menghasilkan angka keamanan (FK) antara 1,20 hingga 1,30.

\section{KESIMPULAN}

Dari analisis stabilitas dengan menggunakan model intermediate material, ternyata hasil-hasil deformasi dan tegangan efektif maksimum berada dalam rentang antara tanah (MohrCoulomb) dan batuan (Hoek-Brown). Deformasi yang terjadi pada model tanah adalah lebih kecil daripada model intermediate material, demikian sebaliknya deformasi yang terjadi pada model intermediate material adalah jauh lebih kecil daripada model untuk batuan. Hal ini disebabkan oleh tekanan air pori pada model Mohr-Coulomb tidak terjadi sama sekali saat kondisi pembebanan tanpa pembebanan. Selain itu, analisis plastis dalam PLAXIS 2 D tidak mempertimbangkan perubahan volume dan disipasi tekanan air pori. Sebagaimana diketahui bahwa proses konsolidasi dan atau rembesan air tanah sesuai dengan tekanan air pori yang terjadi akan berubah seiring dengan waktu. Selanjutnya, dengan adanya perubahan volume akibat konsolidasi atau efek mengembang lapisan tanah akan mempengaruhi besarnya tegangan efektif pada tanah. Dengan demikian, model Mohr-Coulomb dan Hoek-Brown tidak dapat digunakan sepenuhnya, kecuali model intermediate material. 


\section{DAFTAR PUSTAKA}

[1] Atkinson, J.H., Bransby, P.L. 1978, The Mechanics of Soil, An Introduction to Critical State Soil Mechanics, McGraw-Hill, London.

[2] Brinkgreve, R. B. 2007. Manual Plaxis (Indonesia). Belanda: Plaxis B.V.

[3] Brady, B. H., \& Brown, E. T. 2004. Rock Mechanics. New York: Springer.

[4] Bieniawski, Z.T. 1976. Rock mass classification in rock engineering. In Exploration for rock engineering, proc. of the symp., (ed. Z.T. Bieniawski) 1, 97-106. Cape Town: Balkema.

[5] Bieniawski, Z.T. 1989. Engineering rock mass classifications. New York: Wiley.

[6] Barton, N. R., Lien, R. and Lunde, J. 1974. Engineering classification of rock masses for the design of tunnel support. Rock Mech. 6(4), 189-239

[7] Carter, T. G. 1992. A new approach to surface crown pillar design. Proc. 16th. Canadian Rock Mechanics Symposium, Sudbury,75-83.

[8] Carter, T. G. 1992. Prediction and uncertainties in geological engineering and rock mass characterization assessments. Proc. 4th. int. rock mechanics and rock engineering conf., Torino. Paper 1.

[9] Deere, D.U., Hendron, A.J., Patton, F.D. and Cording, E.J. 1967. Design of surface and near surface construction in rock. In Failure and breakage of rock, proc. 8th U.S. symp. rock mech., (ed. C. Fairhurst), 237-302. New
York: Soc. Min. Engrs, Am. Inst. Min. Metall. Petrolm Engrs.

[10] Grimstad, E. and Barton, N. 1993. Updating the Q-System for NMT. Proc. int. symp. on sprayed concrete -modern use of wet mix sprayed concrete for underground support, Fagernes. 46-66. Oslo: Norwegian Concrete Assn.

[11] Hoek, E. and Brown, E.T. 1980. Empirical strength criterion for rock masses. J. Geotech. Engng Div., ASCE 106 (GT9), 10131035.

[12] Lauffer, H. 1958. Gebirgsklassifizierung für den Stollenbau. Geol. Bauwesen 24(1), 46-51.

[13] SMEC, 1974. Geological Map of Jatigede Dam and Surround, Kementerian Pekerjaan Umum, Direktorat Jenderal Sumber Daya Air, Balai Besar Wilayah Sungai Cimanuk-Cisanggarung, Sumedang.

[14] SMEC, 2011. Manual for Geotechnical and Preliminary Environmental Site Assessment (Special Report), Australia.

[15] Singh, B. and Goel, R.K. 1999. Rock mass classification, Elsevier Science Ltd., pp. 34-39.

[16] Terzaghi, K. 1946. Rock defects and loads in tunnel supports. Rock tunneling with steel supports. R.V. Proctor and T.L. White, eds., The Commercial Shearing and Stamping Co., Youngstown, Ohio, 17-99. 